\title{
Species-level and community-level data analyses reveal spatial differences and temporal change in the crustacean zooplankton of a large Canadian lake (Lake Simcoe, Ontario)
}

\author{
Kenneth H. NICHOLLS* and Claudiu TUDORANCEA ${ }^{1)}$ \\ Ontario Ministry of the Environment, C/O Biomonitoring Section, 125 Resources Road, Toronto, ON M9P 3V6 Canada \\ Present address: S-15 Concession 1, RR \#1, Sunderland, Ontario L0C 1H0 Canada \\ ${ }^{1)}$ Faculty of Biology and Geology, "Babes-Bolyai" University, Str. Mihail Kogalniceanu nr. 1, RO-3400 Cluj-Napoca, Romania \\ *e-mail corresponding author: khnicholls@interhop.net
}

\begin{abstract}
Consensus-building univariate and multivariate data analyses were used to identify patterns in space and time over seven years among 12 sampling stations in a $720 \mathrm{~km}^{2}$ hardwater Canadian lake (Lake Simcoe, Ontario, Canada). There were 15 copepods and 26 cladoceran species identified in samples collected throughout the May-October periods of 1986-1992 from Lake Simcoe. Eleven crustacean zooplankters accounted for $88 \%$ of the total average density of all recorded species in the lake. Most of these (the main exceptions being Eubosmina coregoni and Daphnia pulicaria) are ubiquitous taxa with wide environmental tolerances. Multivariate analyses of these data identified spatial differences and a temporal trend in community composition. The use of Cao et al. 's (1997a) "CY-dissimilarity" measure combined with Ward's Linkage clustering algorithm and non-metric multidimensional scaling ordination resulted in several clearly defined groups of sampling units (SUs), which apparently were separated predominantly on the basis of variables related to space (sampling station) and time (year). The 7-year record suggested several lines of evidence for trends in community structure. Averaged over all stations, the yearly intra-station dissimilarities steadily increased $78 \%$ by 1992. The greatest rates of increase in yearly intra-station dissimilarity with 1986 baselines were found for the deeper sampling stations. These whole community-level trends were the net results of a many different patterns of change identified in species-level analyses. Such patterns included increasing densities over the 7-year period of Daphnia longiremis and Diaphanosoma birgei and declining densities of Daphnia pulicaria. Many other taxa showed highest values in the middle years of the study. Community-level temporal trends were least evident at sampling locations in the shallower and warmer Cook's Bay, despite clear trends in several individual species. A significantly greater representation by large-bodied zooplankton species in the latter years of the study was consistent with declining stocks of rainbow smelt (Osmerus mordax) and lake herring (Coregonus artedii), suggesting the associated relaxation of predation pressure as a possible cause. Several species indicative of eutrophic states (Acanthocyclops vernalis, Chydorus sphaericus and Bosmina longirostris) were common in the samples. The scarcity of the calanoid Senecella calanoides and the absence of another classic oligotrophic indicator calanoid, Limnocalanus macrurus in the Lake Simcoe samples suggests impairment of their deep, cold-water habitat and is consistent with the modelled historical loss of hypolimnetic dissolved oxygen in Lake Simcoe.
\end{abstract}

Key words: CY-dissimilarity; eutrophication; NMDS ordination; multivariate, permutation, trends

\section{INTRODUCTION}

Exclusive of the Lautentian Great Lakes, Lake Simcoe is the largest lake in southern Ontario, Canada (Fig. 1) and has been the subject of a comprehensive investigation of its water quality, fisheries, recreational, aesthetic and tourism potential (LSEMS 1995; see also several papers in Vol 13(3) of J. Lake and Reserv. Manage., 1997). Owing to the loss of hypolimnetic dissolved oxygen in late summer (Evans et al. 1996), major concerns exist for at least three species of the Lake Simcoe cold-water fish community: lake trout (Salvelinus namaycush), lake whitefish (Coregonus clupeaformis) and lake herring (cisco), C. artedii). In particular, regular angler catch surveys and index netting conducted by the Ministry of Natural Resources show declining catches of Lake Simcoe lake herring since the early 1980's. Lake trout and lake whitefish populations have been maintained for the past several decades by annual stockings of hatchery-reared fish (McMurtry et al. 1997).

Additional factors besides dissolved oxygen levels in cold-water habitats may be implicated in the decline of natural reproduction of the Lake Simcoe cold-water fish species. Apparent weakening of younger year classes suggests problems in the early life history of these fish, perhaps related to egg survivorship, predation, and/or availability of food for larval or juvenile stages. Several species of Lake Simcoe fish besides lake herring (and including warm-water species) depend on an abundant supply of crustacean zooplankton as their major food source.

Until now, little was known of the status of the Lake Simcoe zooplankton community. These information needs are even more compelling given the recent invasion of the lake by the spiny waterflea (Bythotrephes sp.) in 1993-94 and the zebra mussel (Dreissena polymorpha) in 1994-95, both of which have potential to alter zooplankton community structure, either directly 
or indirectly (Yan \& Pawson 1997; MacIsaac 1996). Because of the heterogenous morphometry and large size of Lake Simcoe [relatively shallow Cook's Bay, relatively deep Kempenfelt Bay and the large moderately deep main lake (Fig. 1)], zooplankton data collected regularly over several years from many locations on the lake are well-suited to multivariate methods of analysis. Nicholls \& Tudorancea (2001a) have previously shown how fuzzy cluster membership coefficients could be used for ranking the importance of crustacean zooplankton species for their contribution to a sampling unit (SU) dendrogram. Their fuzzy cluster analysis also suggested that the crustacean zooplankton community structure might be time- and space-dependent in this lake. In a companion paper using this same data set (12 stations over seven years), Nicholls \& Tudorancea (2001b) concluded that spatial autocorrelation was not significant; however, they demonstrated localized gradients for many zooplankton taxa using trend-surface analysis.

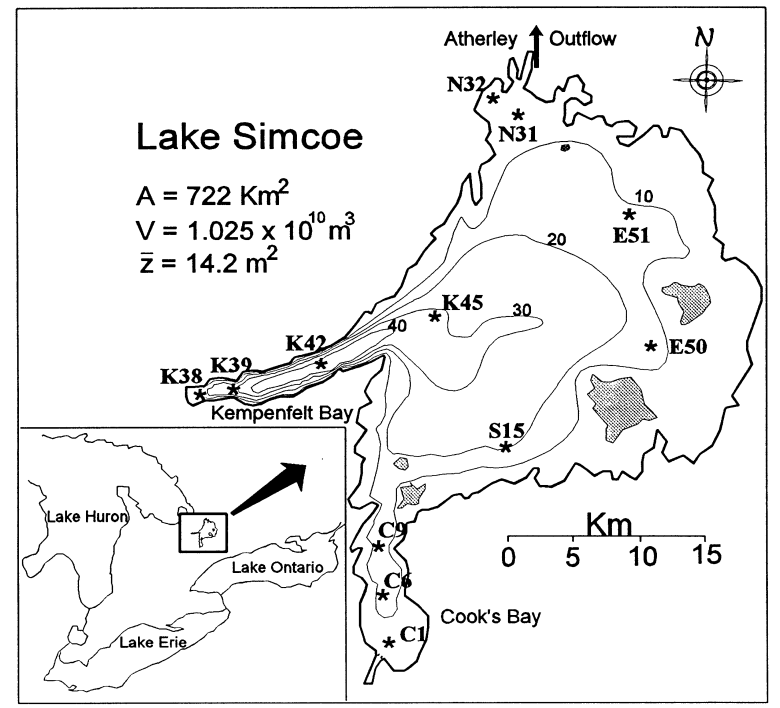

Fig. 1. The location of Lake Simcoe in southern Ontario, Canada. The 10, 20, 30 and $40 \mathrm{~m}$ depth contours, the locations of 12 sampling stations and some morphometric data are also shown $(\mathrm{A}=$ lake area excluding islands; $\mathrm{V}=$ lake volume; $\overline{\mathrm{z}}$ $=$ mean depth).

The main purpose of this paper is to identify elements of inter-annual and spatial variability in the Lake Simcoe crustacean zooplankton community structure using a variety of modern multivariate analyses (e.g. Cao et al. 1997a; Philippi et al. 1998). The data cover the 7-year "background" period, 1986-1992 prior to the establishment of the above-mentioned exotic invaders. Subsequent papers will examine relationships with environmental variables and apparent effects of invading species on the Lake Simcoe zooplankton community.

\section{METHODS}

\subsection{Sampling and laboratory methods}

Zooplankton samples were collected at approximately bi-weekly intervals at each of 12 Lake Simcoe stations (Fig. 1) during the May through October periods of 1986 to 1992 . Samples were taken from vertical tows from one meter above bottom to the lake surface with a modified conical Clarke-Bumpus net ( $1 \mathrm{~m}$ long, $12.5 \mathrm{~cm}$ mouth diameter, $80 \mu \mathrm{m}$ Nitex mesh, net bucket $5.1 \mathrm{~cm}$ diameter) equipped with a flow meter for estimation of net efficiencies. Other details of sample preparation and specimen identification and enumeration are provided in Nicholls \& Tudorancea (2001a).

\subsection{Data analyses methods}

\subsubsection{Species-level analyses}

The grand mean abundance (number $\mathrm{m}^{-3}$ ) of each recorded taxon from all sampling stations over all 7 years was calculated and ranked to categorize abundant, less common and rare taxa. For all but the rarest taxa (i.e. those contributing $<0.5 \%$ of the grand mean), percentage deviations from the Lake Simcoe grand means were plotted (i) for each taxon at each station, to illustrate spatial or inter-station differences among taxa, and (ii) for each taxon for each year, to illustrate temporal differences among taxa. The numbers of recorded taxa were examined at three levels of resolution at each of the 12 sampling stations: (1) total recorded number over all seven years, based on quantitative analyses of approximately 840 samples $(12$ stations $\times 10$ samples $/ y \times$ 7 years); (2) 7-year mean, and (3) individual sample mean.

May-October mean densities of all but the rarest taxa were averaged for each year and further aggregated by sampling station to represent each of the three spatial entities of the lake: Kempenfelt Bay and Cook's Bay (three stations each) and the main lake (four stations). Simple time-density plots of all taxa were constructed to identify consistent temporal patterns (increasing, decreasing, mid-study peaks, mid-study lows).

\subsubsection{Community-level analyses}

(i) Dissimilarity, clustering, ordination

May-October arithmetic mean densities (numbers $\mathrm{m}^{-3}$ ) of all taxa were compiled in a taxon-by-sampling unit matrix. A sampling unit (SU) is defined here as one May-October period at one sampling station. Thus, in all there were 84 SUs (12 stations $\times 7$ years), each of which was designated according to the example "C186"(or C1-86), where, in this case, C1 is the sampling station identifier (Station $\mathrm{C} 1$ ) and 86 identifies the year (1986). A SU $\times$ taxon matrix $(84$ columns $\times 45$ rows) served as the basic unit for further analyses.

Cao et al. (1997a) developed a new dissimilarity measure (CY-dissimilarity index) designed to respond 
to various types of bias common to other methods of computing sample similarity when input data consist of uneven distributions of component taxa - typical attributes of biological communities. In a follow-up study, Cao et al. (1997b) evaluated four cluster analysis algorithms and found that Ward's method, also known as Ward Linkage, or minimum variance clustering (Ludwig \& Reynolds 1988), when combined with the CY-dissimilarity index yielded better structure definition and sampling station discrimination than the other methods. The Canberra metric distance measure, when combined with Ward's method, was " $2^{\text {nd }}$ best"; it was nearly as effective as the CY index in its ability to recognize several types of biases common to most raw data sources. Cao et al.'s (1997a) CY dissimilarity index was calculated for all pairs of Lake Simcoe SUs using all 45 zooplankton taxa. Raw data were not transformed, because the CY dissimilarity method accounts for skewed distributions of taxa inherently (logarithmic terms are a component of the index) and makes a separate data transformation step redundant (Cao et al. 1997b). The CY dissimilarity matrix was entered into 1) SYN-TAX (Podani 1997a) for ordination by nonmetric multidimensional scaling (NMDS) and for clustering by Ward's method, and 2) the PC program MVSP (Kovach 1993) for application of the same clustering procedure (but here listed as the "minimum variance" method) with several runs starting with different randomized data input orders. This was done to confirm the stability of the output, because input order can influence dendrogram structure in some circumstances (Podani 1997b; Oksanen \& Minchin 1997; Tausch et al. 1995). Among all such runs, there was $100 \%$ concordance between pairs of dendrograms generated by the same measure of dissimilarity and the same clustering algorithm (but using different data input orders) determined as the percentage of all SUs that were assigned to the same cluster in both dendrograms (Digby \& Kempton 1987).

To assess the output and build consensus we also developed a matrix of Canberra metric SU dissimilarities which we tested for compatibility with the CY-dissimilarity matrix by determining the concordance between dendrograms produced from both the CY and Canberra metric dissimilarity matrices. Concordance between CY and Canberra metric-based dendrograms (both built by the Ward's Linkage algorithm) was determined in SYN-TAX using a method of comparing multiple dendrogram descriptors for every pair of objects. These descriptors included cophenetic differences, cladistic differences, ultrametric differences and edge matching coefficients, as described by Podani (1994). Comparisons included the Canberra metric distance measures with and without data standardization and transformation $\left(\log _{10}\right)$. Cluster membership divergence was tested for statistical significance using a randomization test with 10,000 simulated distance values (Podani 1997a).

\section{(ii) Characterization of spatial and temporal patterns}

Clarke \& Warwick (1994) described a method for testing the significance of treatment effects on similarity matrices for the special case not covered by their previously published ANOSIM tests (e.g. Clarke \& Green 1988) - that of the "two-way crossed layout without replication". This arises from a sampling design consisting of single samples of multiple species taken at several stations over time. Two null hypotheses are typically generated by this sampling design, which in the context of the Lake Simcoe zooplankton survey, are:

- $\mathrm{N}_{01}$ : there are no year-to-year differences (but allowing for possible station-to-station differences);

- $\mathrm{N}_{02}$ : there are no station-to-station differences (but allowing for possible year-to-year differences.

The procedures for testing these two null hypotheses are described below and essentially follow the Clarke \& Warwick (1994) protocol, except that our basic starting point was the CY dissimilarity matrix, whereas Clarke \& Warwick (1994) started with a Bray-Curtis similarity matrix. In addition, further consensus-building methods were applied e.g. Philippi et al. 1998 - see below).

The significance of both the spatial and temporal components of the main dissimilarity matrix can be separated by segregating the sampling station elements of the matrix (blocks) from the year elements (treatments), and then rerunning the procedures described below with the station and year elements as treatments and blocks, respectively (Figs $2 \mathrm{a}$ and $2 \mathrm{~b}$ ). Partitioning of the inter-station component of overall variability involved the extraction of twelve small triangular matrices (blocks; one block for each Lake Simcoe station) from the final full CY-dissimilarity SU matrix (Fig. 2a). Each block had $n(n-1) / 2=21$ CY-dissimilarity values $(n=7$ years), representing all possible pairs of years for one sampling station. Comparisons among all possible pairs of blocks yielded insight into inter-annual variability because treatments (sampling stations) were held constant (there were no inter-station dissimilarities extracted from the main CY-dissimilarity matrix in the formation of the blocks). We then computed a new dissimilarity matrix from the block correlation coefficients based on all possible pairing of the blocks. These new objects (stations, in this case) were then subjected to a principal coordinates analysis ( $\mathrm{PCOA})$, on the understanding that if the cumulative percentages of eigenvalues were high $(>80 \%)$, thus imparting confidence in the 2-dimensional PCoA, Mantel tests could then be carried out only on those stations suggesting borderline disparities with other stations in the PCoA field. If the cumulative percentages of eigenvalues were low, there was no purpose in pursuing the PCoA approach. Instead, a series of selective permutation tests in a narrowed range of the correlation coefficients could be run with the objective of identifying a threshold correlation coefficient below which the blocks are not likely drawn from the 

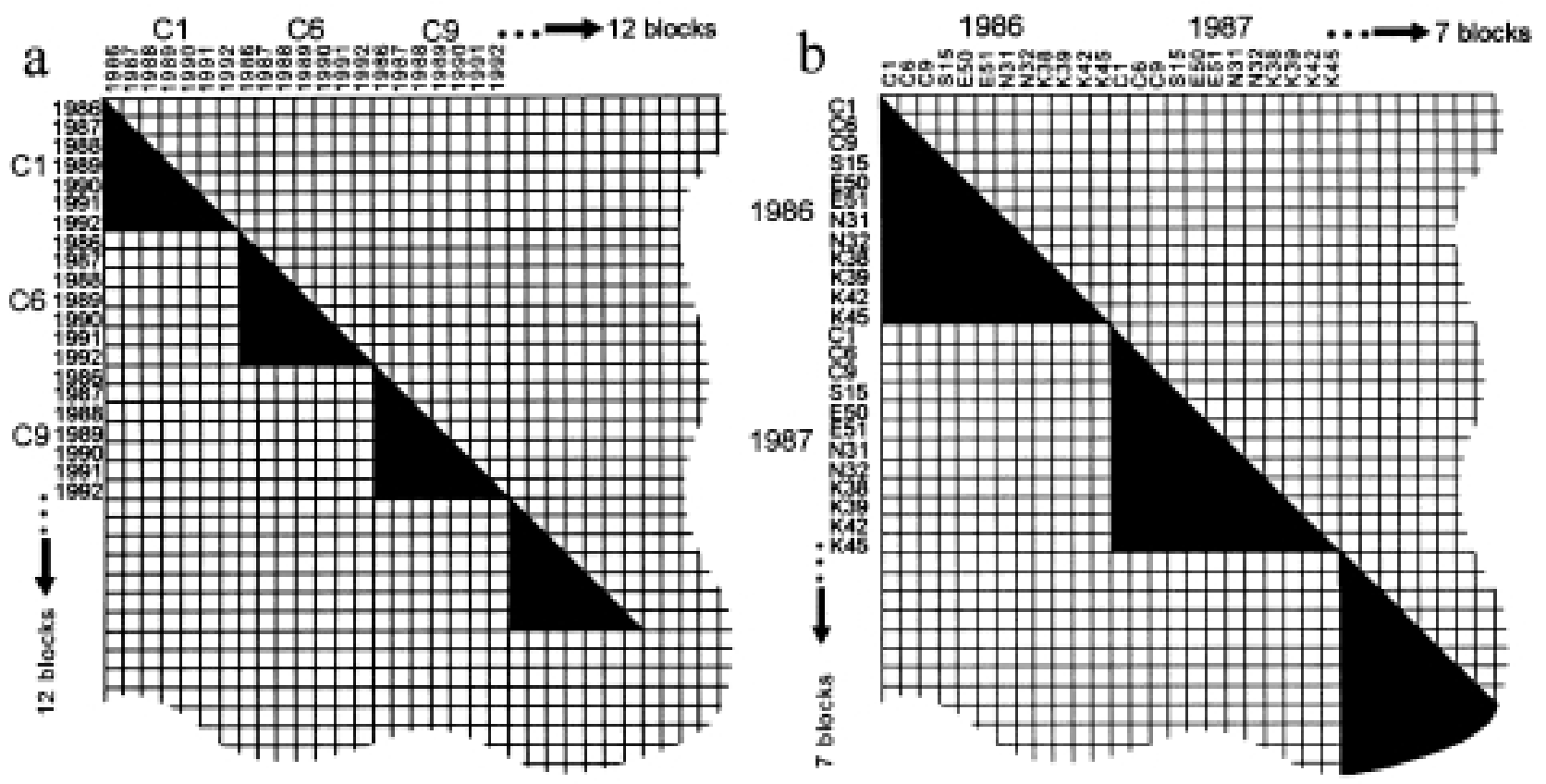

Fig. 2. Organization of the main SU matrix into (a) 12 station blocks with inter-year pairings, and (b), 7 year blocks with interstation pairings.

same population (i.e. statistically different by the Mantel test). The process was repeated after extraction from the main CY-dissimilarity matrix of seven new annual blocks representing the 1986-1992 period wherein stations were "treatments"(Fig. 2b). In a way similar to that described above for the determination of inter-annual variablility, inter-station variability was determined. Within-year CY-dissimilarity values for all station pairs were extracted from the main CY-dissimilarity matrix and expressed as a mean which was then averaged over all years to identify dominant spatial (inter-station) differences in taxonomic composition.

The 12 block inter-comparisons revealed how well the year-to-year differences at a station were duplicated at other stations. Stations could have totally different species composition but still show a high correlation coefficient if the years influenced the dissimilarity values in the same relative way (inter-year pairings go up or down similarly over the years at both stations). This approach was therefore useful for identifying how yearly influences might be operating (e.g. do they affect shallow and deep stations equally?).

The questions 1) what years have significantly different zooplankton community structure (across all sampling stations), and 2) what stations have significantly different species compositions (independent of annual differences), were addressed as follows: The temporal component of the main CY-dissimilarity matrix was extracted by calculating the mean CY-dissimilarities for each year with SUs from all other years. For example, the measure of dissimilarity of 1986 with all other years was based on the average CY-dissimilarity of C1-86 paired with all other SUs, C6-86 paired with all other SUs, C9-86 paired with all other SUs, and so on. Columns of CY-dissimilarity values for each of the other years, 1987-1992 were assembled in a similar way. Excluded from each column were all intra-year pairings (e.g. the 1986 column did not include CY-dissimilarity values from any pair of stations sampled in 1986). Thus, the mean of each column represented the average dissimilarity of stations sampled in the given year with all other SUs. The number of pairings for each of the seven columns (7 years) was therefore $\mathrm{N}=$ $\mathrm{S}[\mathrm{S}(\mathrm{Y}-1)]=864$, where $\mathrm{S}$, the number of stations $=12$ and $Y$, the number of years $=7$.

Similarly, the spatial component of the overall CYdissimilarity matrix of all possible SU combinations was extracted by compiling 12 columns of dissimilarity values derived from pairings of each station with all other stations. Excluded from a given station column were all intra-station pairings, so for example, the $\mathrm{C} 1$ column contained the dissimilarity values for all C1 SUs (C1-86, C1-87, etc.) with all other SUs, except C1. The column mean was then the average dissimilarity of Station $\mathrm{C} 1$ with all other stations across all years. In this case, the number of variates contributing to the column mean was $\mathrm{N}=\mathrm{Y}(\mathrm{Y}[\mathrm{S}-1])=539$, where $\mathrm{Y}=7$ years and $\mathrm{S}=12$ stations.

Because these columns contained overlapping data elements (dissimilarity measures were based on station 
Tab. 1. Average density (number $\mathrm{m}^{-3}$ ) and resultant abundance ranking (Rank-1) of each taxon for all 12 Lake Simcoe sampling stations over the period 1986-1992. Also shown are the overall rankings (Rank-2) for the importance of each taxon in SU dendrogram structure based on three different ranking methods (see Nicholls \& Tudorancea 2001a).

\begin{tabular}{|c|c|c|c|}
\hline Density $\left(\# \mathrm{~m}^{-3}\right)$ & Rank-1 & Rank-2 & Taxon \\
\hline 0.9 & 37 & 27.7 & Acroperus harpae Baird \\
\hline 4.83 & 28 & 27.0 & Alona spp. \\
\hline 5789.6 & 5 & 4.7 & Bosmina (Bosmina) longirostris (O.F. Müller) \\
\hline 149.5 & 17 & 25.3 & Ceriodaphnia sp. \\
\hline 111.9 & 19 & 25.3 & Chydorus sphaericus (O.F. Müller) s.l. \\
\hline 0.42 & 40 & 33.0 & Daphnia ambigua Scourfield \\
\hline 1.81 & 29 & 32.3 & Daphnia catawba Coker \\
\hline 1.76 & 30 & 36.0 & Daphnia dubia Herrick, emend. Herrick \\
\hline 3147.1 & 6 & 6.0 & Daphnia galeata mendotae Birge \\
\hline 147.2 & 18 & 24.7 & Daphnia longiremis Sars \\
\hline 29 & 23 & 14.0 & Daphnia parvula Fordyce \\
\hline 449.1 & 14 & 25.0 & Daphnia pulicaria Forbes, emend. Hrbácek \\
\hline 1874.6 & 8 & 5.0 & Daphnia retrocurva Forbes \\
\hline 1915.2 & 7 & 6.7 & Bosmina (Eubosmina) coregoni (Baird) \\
\hline 0.49 & 38 & 28.0 & Eurycercus lamellatus (O.F. Müller) \\
\hline 76 & 20 & 28.0 & Holopedium gibberum Zadach \\
\hline 0.19 & 43 & 40.0 & Ilyocryptus spinifer Herrick \\
\hline 6.4 & 27 & 29.0 & Leptodora kindtii (Focke) \\
\hline 1.75 & 31 & 34.0 & Macrothrix laticornis Fischer (Jurine) \\
\hline 0.33 & 41 & 34.0 & Pleuroxus hamulatus Birge \\
\hline 6.78 & 26 & 25.7 & Sida crystallina (O.F. Müller) \\
\hline 0.42 & 39 & 33.3 & Simocephalus serrulatus (Koch) \\
\hline 1.02 & 34 & 30.3 & Simocephalus vetulus (O.F. Müller) \\
\hline 0.97 & 36 & 29.7 & Bosmina (Eubosmina) longispina (Leydig) \\
\hline 593.4 & 13 & 9.3 & Diaphanosoma birgei Koř́nek \\
\hline 55.7 & 21 & 27.3 & Daphnia sp (unidentified) \\
\hline 16606.3 & 2 & 6.7 & Calanoid copepodid \\
\hline 964 & 10 & 10.3 & Leptodiaptomus minutus (Lilljeborg) \\
\hline 329.7 & 15 & 13.0 & Skistodiaptomus oregonensis (Lilljeborg) \\
\hline 265.4 & 16 & 16.0 & Leptodiaptomus sicilis (Forbes) \\
\hline 20.1 & 24 & 29.0 & Epischura lacustris Forbes \\
\hline 0.16 & 44 & 42.3 & Senecella calanoides Juday \\
\hline 6785.4 & 4 & 6.7 & Calanoid nauplius \\
\hline 15871.2 & 3 & 6.0 & Cyclopoid copepodid \\
\hline 1380.2 & 9 & 9.7 & Diacyclops thomasi (Forbes) \\
\hline 0.26 & 42 & 41.0 & Cyclops scutifer Sars \\
\hline 53.7 & 22 & 23.7 & Acanthocyclops vernalis (Fischer) \\
\hline 0.15 & 45 & 34.7 & Macrocyclops albidus (Jurine) \\
\hline 755.1 & 11 & 11.3 & Mesocyclops edax (Forbes) \\
\hline 1.03 & 33 & 34.0 & Orthocyclops modestus (Herrick) \\
\hline 21943.5 & 1 & 6.3 & Cyclopoid nauplius \\
\hline 8.28 & 25 & 26.7 & Eucyclops serrulatus (Fischer) \\
\hline 0.49 & 38 & 35.0 & Eucyclops neomacruroides Dussart \& Fernando \\
\hline 644.2 & 12 & 10.3 & Tropocyclops extensus Kiefer \\
\hline 1.02 & 35 & 31.0 & Mesocyclops americanus Dussart \\
\hline
\end{tabular}

pairs), the columns were not independent; conventional statistical evaluations of the differences in the column means (t-tests, Mann-Whitney U-tests) were therefore not appropriate. Frequency distributions for the means of each column were generated by bootstrapping 10,000 resamplings from each column (Péladeau \& Lacouture 1993), thus generating a 95\% confidence interval around each columnar mean against which each of the other means in the set could be compared.

Detection of temporal trends in zooplankton community composition was applied separately to each of the 12 Lake Simcoe sampling stations, after assignment of baseline status to the year 1986, the first year of this investigation. The rank correlation between time and dissimilarity of each of the years 1987-1992 with the 1986 baseline was considered to be a measure of temporal trend in community composition. These statistics test the hypothesis that D1-1 = D1-2 = D1-3 = D1-4 = D1-5, against the alternative that D1-1 $<$ D1-2 $<$ D1-3 $<$ D1-4 $<\mathrm{D} 1-5$, where Di-j is the dissimilarity between dates $\mathrm{i}$ and $\mathrm{j}$, and date 1 is the baseline (Philippi et al.1998).

\section{RESULTS}

Of the two major groups, copepods (15 species) and cladocerans (26 species), the Cladocera dominated the Lake Simcoe zooplankton in terms of densities of adults. Bosmina (Bosmina) longirostris, Bosmina 
(Eubosmina) coregoni, Daphnia galeata mendotae, D. retrocurva and Diaphanosoma birgei with lakewide 7year average densities ranging between 593 and 5790 individuals $\mathrm{m}^{-3}$ were the most abundant species. Among the copepods, Leptodiaptomus minutus, L. sicilis, Skistodiaptomus oregonensis, Diacyclops thomasi, Mesocyclops edax and Tropocyclops extensus were the most abundant with lake-wide 7-year average densities ranging between about 265 and 1380 individuals $\mathrm{m}^{-3}$ (Tab. 1). However, the bulk of the contribution by copepods was from immature stages, especially cyclopoid nauplii with a 7-year whole lake average of nearly $22,000 \mathrm{~m}^{-3}$ (Tab. 1).
Daphnia pulicaria, whose densities at the six shallow stations averaged $64 \%$ below those of the deep-water stations. Leptodiaptomus minutus was above average in abundance at the main lake shallow stations (E50, E51, N31, N32) but was under-represented in Cook's Bay and at Stations K39, K42 and K45. Cyclopoid nauplii and copepodids were much more abundant in Cook's Bay (Station C1) than elsewhere (Fig. 3).

Year-to-year patterns in the relative importance of dominant taxa were apparent (dominant taxa were those contributing $>0.5 \%$ to the lake-wide, multi-year grand mean crustacean zooplankton density). In 1986, all dominant taxa were present at densities below their re-

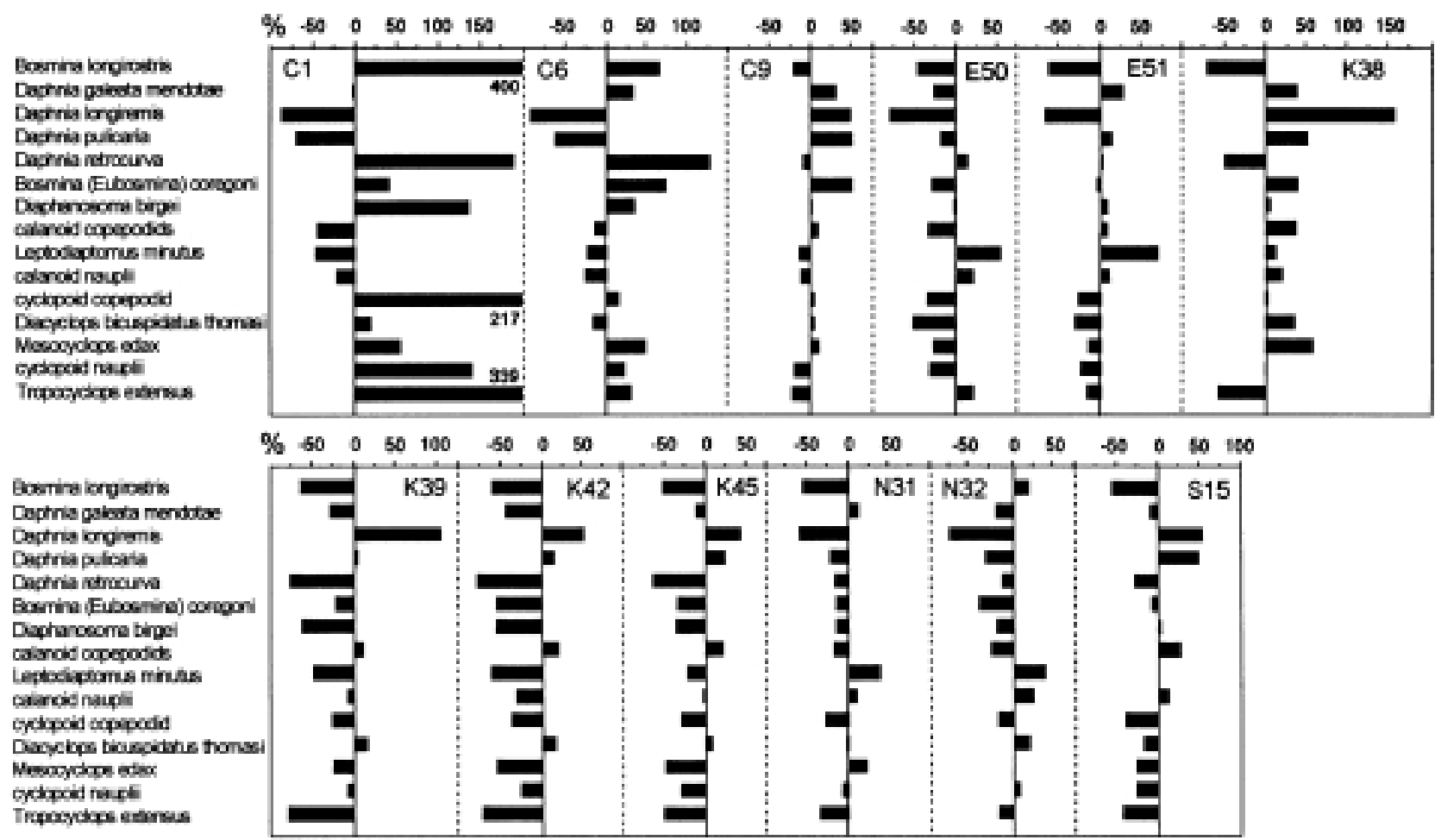

Fig. 3. Percentage deviations from the grand mean for all sampling stations (zero $\%$ lines) of all zooplankton taxa contributing $>0.5 \%$ of the 7-year (1986-1992) average total zooplankton density.

There were clear patterns in the relative importance of some zooplankton taxa at several sampling stations. For example, Cook's Bay stations C1 and C6 showed much higher representation of Bosmina longirostris, Daphnia retrocurva, Bosmina (Eubosmina) coregoni, Diaphanosoma birgei and Tropocyclops extensus than the other Lake Simcoe stations, although Station K38 was an exception for M. edax and B. coregoni (Fig. 3). The taxon most under-represented at the shallow stations (C1, C6, E50, E51, N31 and N32) was Daphnia longiremis, with average densities $153 \%$ below its average recorded for the remaining six deep-water stations. A similar, but less well-defined pattern was found for spective grand means, except for Daphnia pulicaria, whose lake-wide average exceeded its grand mean by over $200 \%$. By 1987 , the relative importance of $D$. pulicaria had declined such that its lake-wide mean exceeded its grand mean by $97 \%$; by $1988, D$. pulicaria densities averaged $26 \%$ below the 7-year grand mean for this species and never recovered in four subsequent years (Fig. 4). In contrast, Daphnia longiremis was poorly represented during the first four years of the study (averaging 88\% below its grand mean). It assumed a much more dominant role during 1990, 1991 and 1992 with contributions of $168 \%, 10 \%$ and $175 \%$ above the overall $D$. longiremis grand mean (Fig. 4). 


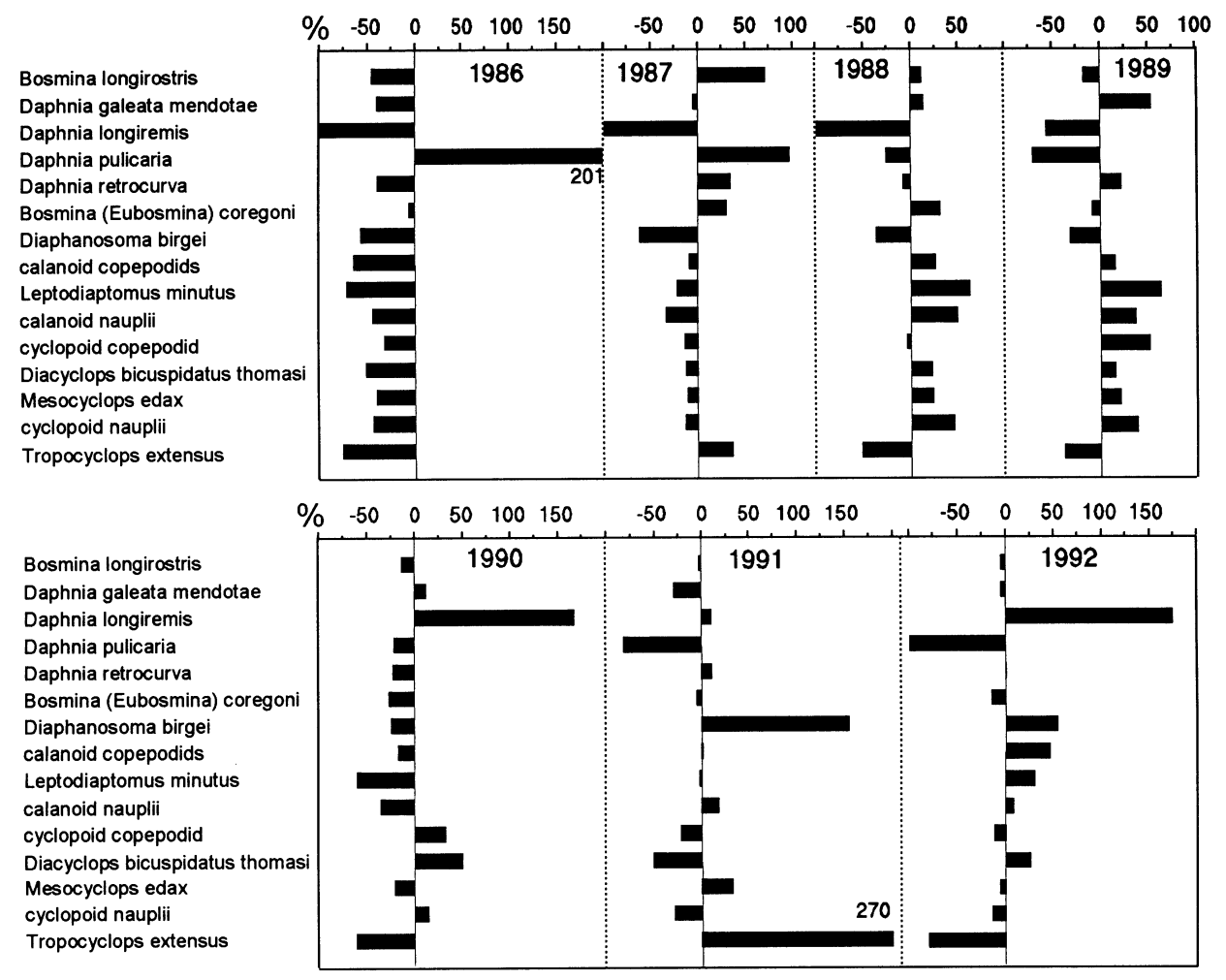

Fig. 4. Percentage deviations from the grand mean for all years (zero \% lines) of all zooplankton taxa contributing $>0.5 \%$ of the 7 year (1986-1992) average total zooplankton density.

As a group, the copepods increased in importance from 1986 through 1989. Thereafter some taxa (e.g. Leptodiaptomus minutus, Mesocyclops edax) declined in 1990, but recovered to levels close to their long term average densities by 1991-1992. No clear pattern could be identified for Tropocyclops extensus, whose densities were well above its overall grand mean in 1991, but were 38 to $79 \%$ less than the grand mean during five of the other six years (Fig. 4).

Of the 41 crustacean zooplankton taxa identified in Lake Simcoe (Tab. 1, excluding unidentified immature stages of copepods), 36 were found at Station C1 (Fig. 5). Only Daphnia dubia, Ilyocryptus spinifer, Senecella calanoides, Cyclops scutifer and Eucyclops neomacruroides were not found in samples from Station C1. Five other taxa, Daphnia ambigua, Macrothrix laticornis, Pleuroxus hamulatus, Simocephalus serrulatus, and S. vetulus were found only at Station C1, but in only 1-4\% of samples from this location. Total number of recorded species at the other stations ranged from 23 (Station N31) to 27 (Stations K42 and K45) for the period 19861992 (Fig. 5).

The highest of the annual total numbers of species recorded was 31, in 1992 at Station C1, while the lowest was 14, recorded for K38 in 1986, C9 and K42 in 1988, and S15 in 1992 (Fig. 5).

Large reductions in species richness resulted from rarefaction of the original data. Generally, the annual average total number of taxa found for each station was about $30 \%$ lower than the overall 7-year total. Similarly, the numbers of taxa found in individual samples (averaging about 10 taxa at the 12 sampling stations) was about $40 \%$ below the annual station totals (Fig. 5).

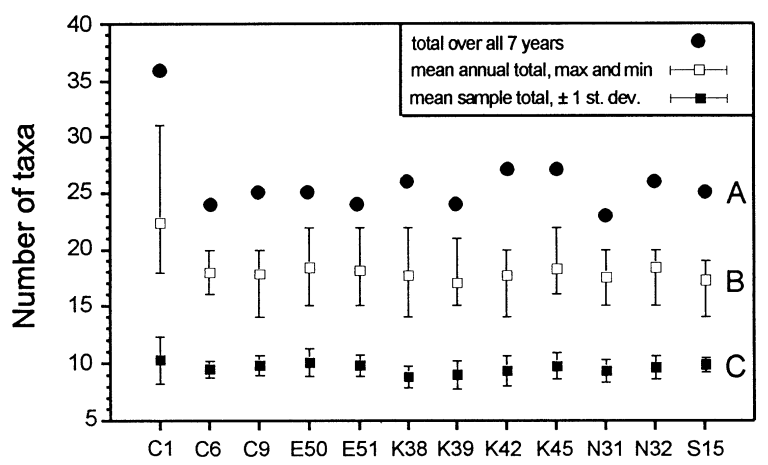

Fig. 5. Total number of taxa (excluding unidentified immature stages) recorded over the entire 7-year period, 1986-1992 (A) at each of the Lake Simcoe sampling stations. Panel B is the total number of taxa found over a May-October sampling period averaged (with maxima and minima) for the 7-year period. Panel $\mathrm{C}$ is the number of taxa found on individual sampling dates averaged for annual periods, then averaged $( \pm 1$ st. dev.) for the entire 7-year period.

Four cladocerans (Bosmina (Eubosmina) coregoni, B. longirostris, Daphnia galeata mendotae, and D. ret- 
Tab. 2. Sample percentage occurrences of selected crustacean zooplankton taxa. Percentages shown are ranges among the 12 Lake Simcoe sampling stations, 1986-1992.

\begin{tabular}{ll}
\hline VERY COMMON TAXA & RELATIVELY COMMON TAXA \\
Bosmina (Eubosmina) coregoni (86-96\%) & $\begin{array}{l}\text { Daphnia pulicaria }(17-63 \%) \\
\text { Bosmina longirostris }(80-97 \%)\end{array}$ \\
$\begin{array}{l}\text { Laphnia galeata mendotae }(79-95 \%) \\
\text { Daphnia retrocurva }(62-86 \%)\end{array}$ & Skistodiaptomus oregonensis $(34-62 \%)$ \\
Diacyclops thomasi $(81-100 \%)$ & \\
Leptodiaptomus minutus $(58-96 \%)$ & SKEWED DISTR., UNCOMMON TAXA \\
Mesocyclops edax $(73-81 \%)$ & (Group a) \\
& Eucyclops neomacruroides $(0-4 \%)$ \\
WIDESPREAD, LESS COMMON TAXA & (Group b) \\
Ceriodaphnia Spp. $(3-57 \%)$ & Alona spp $(0-10 \%)$ \\
Chydorus sphaericus $(10-46 \%)$ & Daphnia parvula $(0-15 \%)$ \\
Daphnia longiremis $(10-46 \%)$ & Daphnia sp. (unident.) $(3-22 \%)$ \\
Holopedium gibberum $(7-40 \%)$ & Sida crystallina $(0-18 \%)$ \\
Leptodora kindtii $(3-11 \%)$ & Acanthocyclops vernalis $(0-26 \%)$ \\
Epischura lacustris $(7-28 \%)$ & Eucyclops serrulatus $(0-8 \%)$ \\
\hline
\end{tabular}

rocurva) and three copepods (Diacyclops thomasi, Leptodiaptomus minutus and Mesocyclops edax) can be categorized as very common in Lake Simcoe, having occurred in $62-100 \%$ of samples from all sampling stations (Tab. 2). These taxa were also very abundant, ranking $3^{\text {rd }}, 1^{\text {st }}, 2^{\text {nd }}, 4^{\text {th }}, 5^{\text {th }}, 6^{\text {th }}$ and $7^{\text {th }}$, respectively, in overall lake-wide densities (Tab.1, but excluding the rankings for immature forms). Four taxa were classed as "relatively common", with occurrences in samples ranging from 17 to $65 \%$ (Tab. 2). Of these, D. pulicaria was more prevalent outside of Cook's Bay; it was found in $17 \%$ of samples from Station $\mathrm{C} 1$ and in $29 \%$ of samples from Station C6, but at all other stations it was present in $36-63 \%$ of samples.

There were several taxa with apparently spatially skewed distributions; most of these (Group b in Tab. 2) were relatively common at Station $\mathrm{C} 1$ in Cook's Bay, but rare elsewhere. These included species of Alona, which were found in $10 \%$ of the samples from Station $\mathrm{C} 1$, but only $0-4 \%$ of samples from other stations. Three other cladocerans, Daphnia parvula, an unidentified Daphnia species, and Sida crystallina, were found at Station $\mathrm{C} 1$ in $15 \%, 22 \%$, and $18 \%$ of the samples, respectively, but in $<5 \%,<9 \%$, and $<5 \%$ of samples at all other sampling stations. Similar distributions were found for the copepods, Acanthocyclops vernalis and Eucyclops serrulatus, which occurred at Station $\mathrm{C} 1$ in $26 \%$ and $8 \%$ of the samples, respectively, but in only 0 $9 \%$ and $0-3 \%$ of samples from other stations (Tab. 2). The only other species of Eucyclops found in Lake Simcoe (E. neomacruroides) was restricted to the deepwater stations, K39, K42 and K45 in 4\%, $1 \%$ and $1 \%$ of samples, respectively.

An additional category of six widespread but less common taxa occurred at all sampling stations at frequencies ranging between $3 \%$ and $57 \%$. These included Ceriodaphnia spp., Chydorus sphaericus, Daphnia longiremis, Holipedium gibberum, Leptodora kindtii and Epischura lacustris (Tab. 2).
The combination of 12 sampling stations and seven years generated a total of 84 "station-years" or sampling units (SUs) for cluster analysis based on their May-October average zooplankton species compositions. The use of the CY dissimilarity measure combined with Ward's Linkage clustering algorithm resulted in several clearly defined groups of SUs that apparently were separated predominantly on the basis of year and another variable perhaps related to station depth (Fig. 6). The only exception to this was Station C1, all seven years of which, along with C6-91, formed Group I of the 7-group solution. Excluding Group I, eight of the 11 remaining 1990 SUs were found in Group II (Fig. 6). All of the remaining 1992 SUs were found with six of the remaining 1991 stations in Group III. Group IV was comprised of deep-water stations (see Fig. 1) including half of the 1988 SUs. Groups V and VI were comprised predominantly of the 1987,1988 and 1989 SUs, $83 \%$ of which were from deep-water locations. Group VII contained all of the 1986 SUs (again with the exception of Station $\mathrm{C} 1$ ), and included both deep-water and shallowwater locations (Fig. 6).

The dendrogram built from the untransformed Canberra metric (not illustrated to save space) showed very good agreement with the dendrogram derived from the CY dissimilarities. The statistical significance of the cluster membership divergences (distance $=1763.11$ ) in these two dendrograms was tested using a randomization procedure to generate a frequency distribution of distances $(n=10,000)$. The observed value of 1763.11 is very unlikely to result from randomly generated dendrograms since it fell well outside the $95 \%$ boundaries of the normally distributed random values (Fig. 7). Differences between the two dendrograms based on Ward's Linkage, using the CY dissimilarity index in one and the Canberra metric distance in the other, can therefore be considered to be statistically insignificantly and therefore lends considerable confidence to the interpretation of the dendrogram based on CY-dissimilarities. Still, 


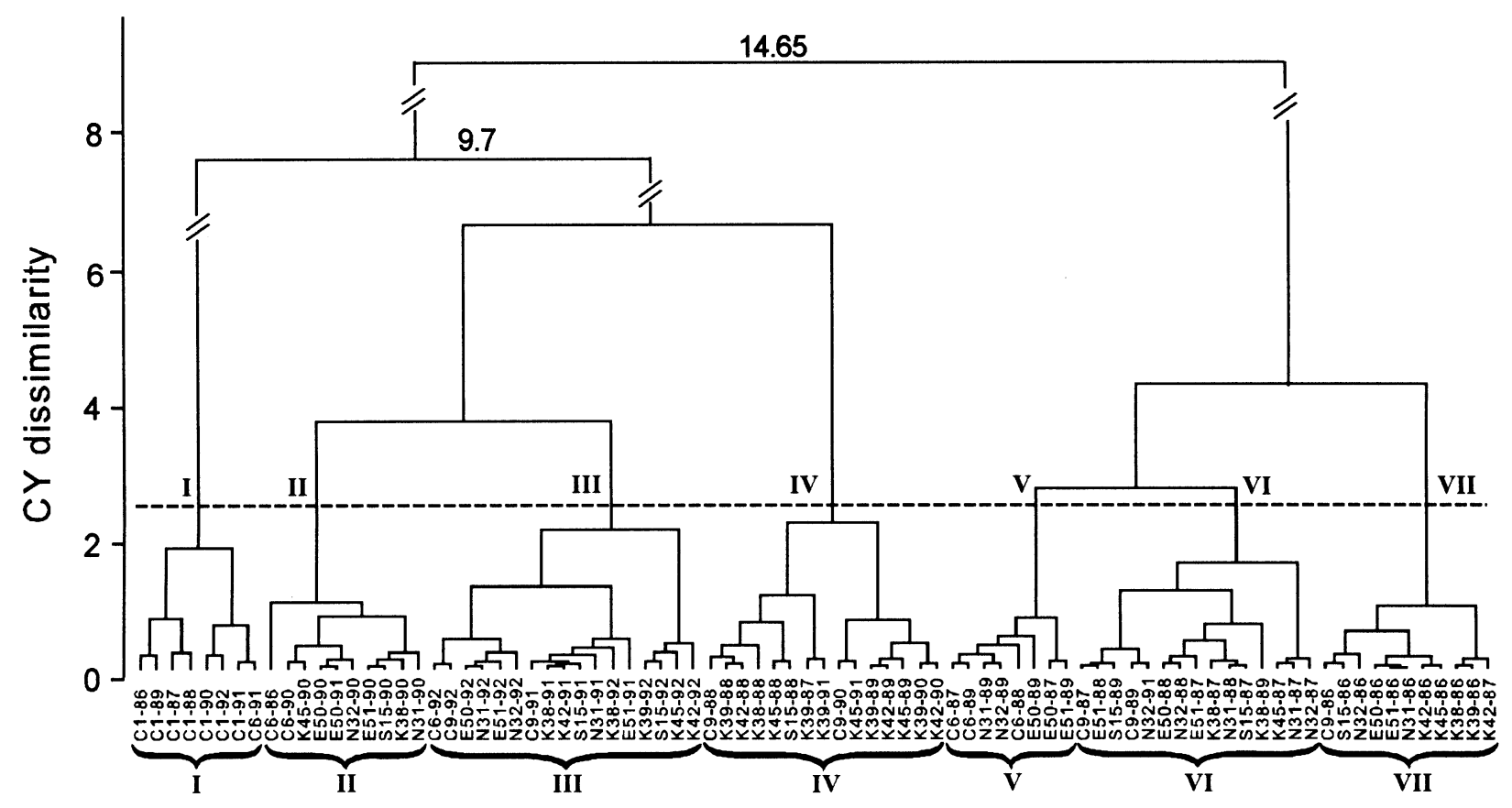

Fig. 6. Clustering of all SUs based on CY dissimilarity coefficients and Ward Linkage, using 45 zooplankton taxa (Tab.1).

there were noticeable differences between them; in the Canberra metric-based dendrogram, 1) the 1992 SUs were divided into two sub-clusters, apparently distinguished by station depth, 2) C1-87 and C1-88 were identified as being very different from the other $\mathrm{C} 1$ years, while the five remaining $\mathrm{C} 1$ years were segregated from all other SUs at a higher level than in the CY-based dendrogram, 3 ) the remaining (excluding $\mathrm{C} 1$ ) shallower stations (N31, N32, E50, E51, C6) were not as well separated from the deep-water stations as in the CY-based dendrogram.

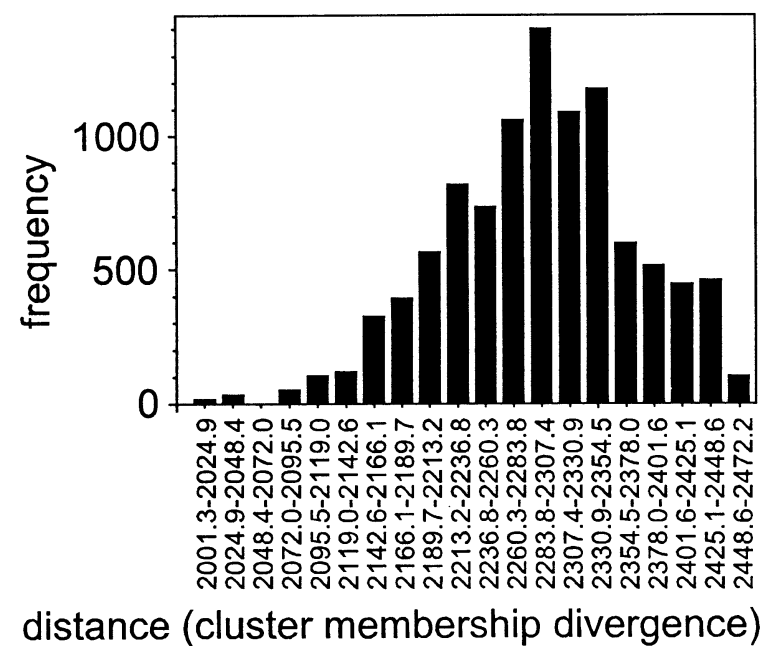

Fig. 7. Frequency distributions of the randomized cluster membership divergences $(10,000$ simulations $)$ in comparisons of dendrograms built from both CY dissimilarities and Canberra metric distances for the sampling unit (SU) clustering.
The gross differences among the zooplankton community structures of all 84 SUs as revealed by the NMDS ordination (Fig. 8a) were similar to those depicted in the CY-dissimilarity dendrogram. Most noticeable were the outlying positions of all station $\mathrm{C} 1$ SUs. C691 occupied an intermediary position between the block of C1 SUs and the remaining Lake Simcoe SUs, consistent with its grouping in the CY-dissimilarity dendrogram. The C1 group also included C686, which did not show an especially high affinity for this group in the dendrogram, where it was more closely allied with several SUs from 1990. At the opposite pole of the ordination (where axis scores for both axes were negative) were several K-station SUs, notably K38 and K39. The remaining $\mathrm{K}$ stations and the other deep-water stations, S15 and C9 were positioned closer to axis scores of zero, while the central area of the ordination field was dominated by the shallower stations N31, N32, E50, E51 and C6 (Fig. 8a). The 2-dimensional NMDS ordination was apparently a very reasonable representation of inter-SU dissimilarities (Fig. 8b). Thus it is significant that the temporal similarities which were suggested in the CY-dissimilarity dendrogram were also apparent (though less easily visualized) in the ordination (Fig. 8a). The 1990-1992 SUs dominated clusters II and III of the dendrogram while clusters VI and VII were best represented by 1986 and 1987 SUs. In the ordination, these two temporal groups of SUs had a tendency to be located in regions defined by axis I scores $>0$ and $<0.05$, respectively.

The taxa contributing most to overall zooplankton density were also those taxa determined by three separate ranking methods (Nicholls \& Tudorancea 2001a) to 
be most important in SU cluster definition. The Pearson product moment correlation coefficient for Rank-1 and Rank-2 (Tab. 1) was $r=0.923$. Excluding immature stages, abundant taxa (high Rank-1 scores) with important contributions to the SU clusters (high Rank-2 scores) included Bosmina longirostris, B. coregoni, Daphnia galeata mendotae, Daphnia retrocurva, Leptodiaptomus minutus, and Diacyclops thomasi with Rank2 ranks of 4.67, 6.67, 6.0, 5.0, 10.33, and 9.67, respectively (Tab.1).
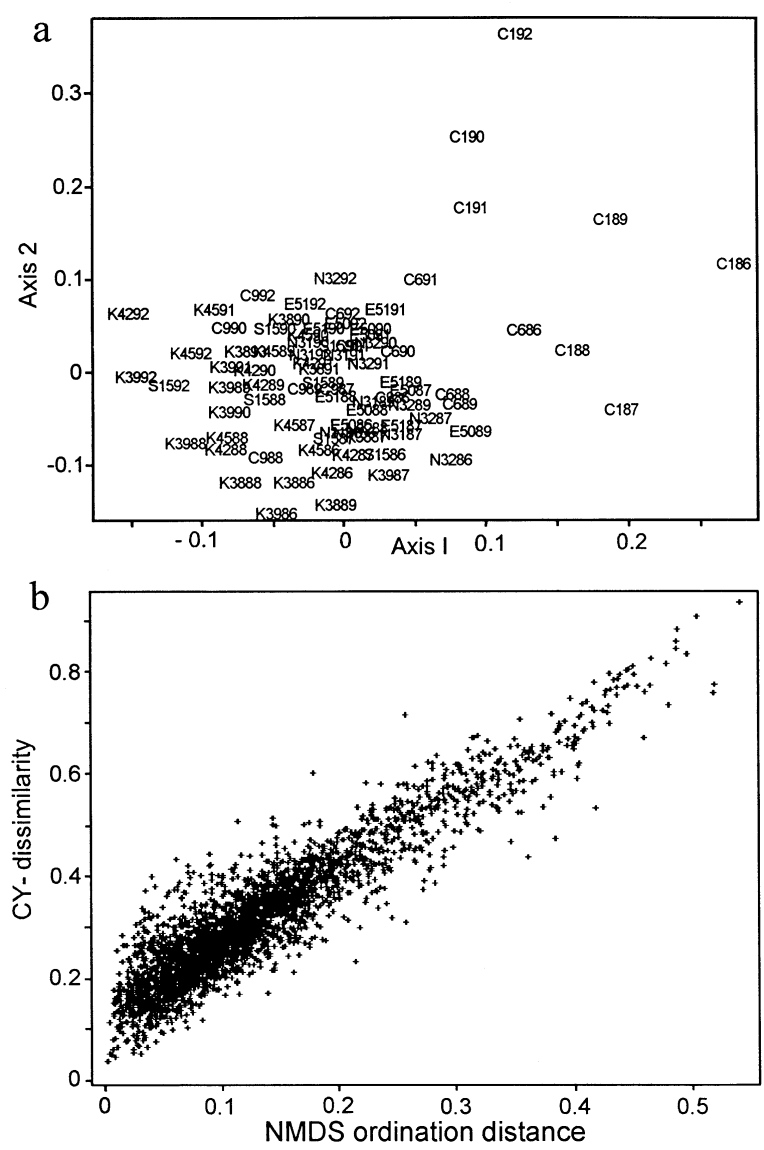

Fig. 8. (a) Non-metric multidimensional scaling ordination of all SUs based on CY-dissimilarity coefficients, using 45 zooplankton taxa (Tab.1). (b) Relationship between calculated CY-dissimilarities for all pairs of SUs and the distance between all corresponding pairs of SUs in the NMDS ordination field.

Consistent with the CY-dissimilarity classification and ordination of SUs, Station C1 had the highest average dissimilarity with all other stations over all years, followed by Station K39, with the remaining stations showing much lower average dissimilarities (Fig. 9). The average dissimilarity of Station $\mathrm{C} 1$ with all other stations $(0.626)$ was nearly twice as high as that $(0.326)$ calculated for Station N31, which had the lowest measure of zooplankton community dissimilarity among all stations. It is noteworthy that Stations E50 and E51 (stations in relatively close proximity in the eastern part of the lake) were not significantly different with respect to their zooplankton community dissimilarities with other stations, while at the north end of the lake, Station N32 had significantly higher dissimilarities with all other stations than did N31 (Fig. 9). Stations C1, C9, $\mathrm{K} 42, \mathrm{~K} 45$ and $\mathrm{S} 15$ all had their maximal dissimilarities with other stations during 1992, while Stations E50, E51, K38, K39, N31 and N32 had their maximal dissimilarities with all other stations during 1989. For Station $\mathrm{C} 6$, the maximum average dissimilarity with all other stations occurred in 1986.

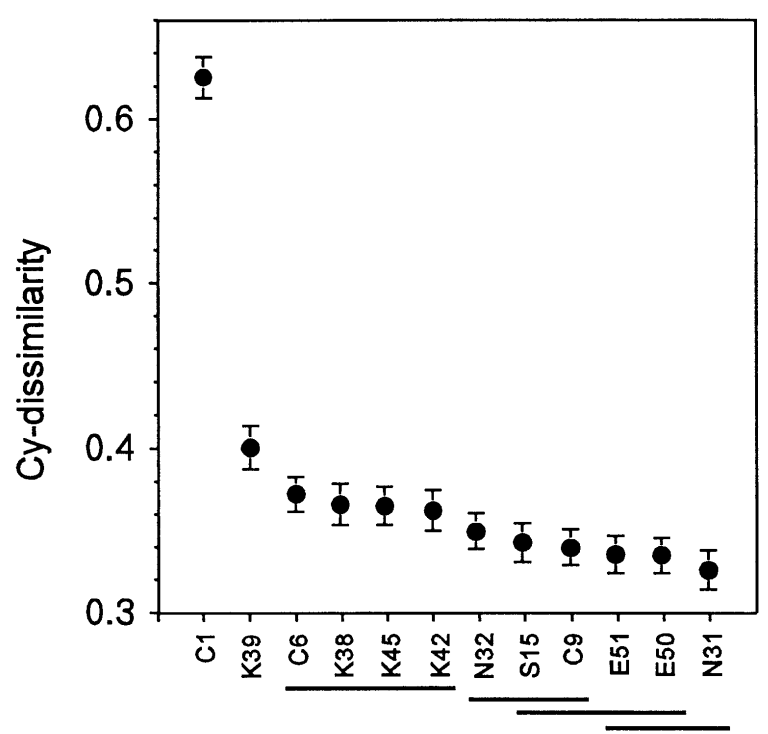

Fig. 9. Seven-year (1986-1992) average CY-dissimilarities (95\% bias-corrected bootstrap confidence intervals) of each station with all others. Stations underscored by the same line are not significantly different $(P<0.05)$.

Zooplankton community structure during 1992 and 1986 was significantly different from all other years (Fig. 10). On average, community structures during 1988 and 1990 were not significantly different, as was the case for 1989 and 1990. Similarly, average zooplankton community structures measured during 1987 , 1989 and 1991 could not be distinguished statistically (Fig. 10).

The pattern of average inter-station dissimilarity was not significantly different from those determined for each separate year. Cophenetic correlation analyses of all seven inter-station CY dissimilarity matrices (one for each of the years 1986-1992) produced correlation coefficients (r) ranging from 0.525, for the 1989 and 1991 pair of matrices, to 0.839 , for the $1987-1992$ pair (Fig. 11).

When these coefficients were expressed as a distance metric (1-r), principal coordinates analysis did not reveal any clearly "outlying" years; although the cumulative percentage of the first two eigenvalues was only 
$58 \%$, so it is doubtful if this two-dimensional ordination adequately portrayed the inter-year distances. Permutation tests of each pair of annual matrices more conclusively established the lack of significant difference between any of the annual pairings at probability levels $<5 \%$ (Fig. 11).

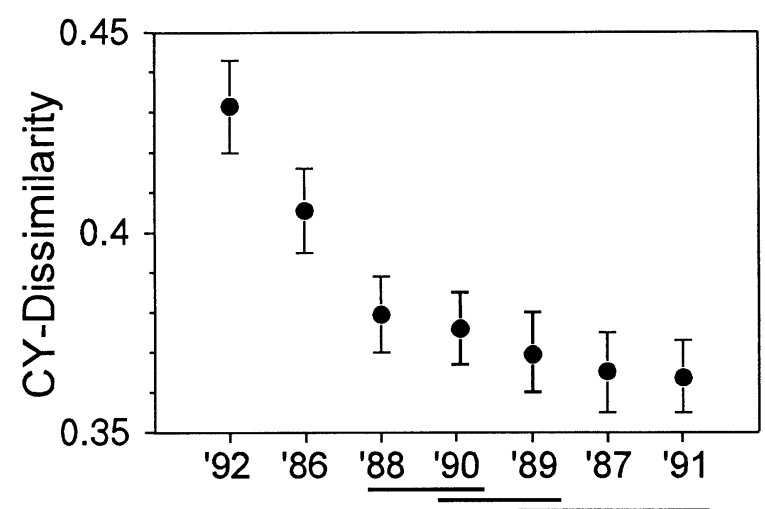

Fig. 10. Mean CY-dissimilarities (95\% bias-corrected bootstrap confidence intervals) for each year of the 1986-1992 sampling period, arranged in descending order. Years underscored by the same line are not significantly different $(P<$ $0.05)$. Excluding all intra-year pairs, there were 684 pairs of SUs represented under each of the years. For example, the 1992 data point represents the mean dissimilarity of each station sampled in 1992 with each of the other stations sampled in all other years.

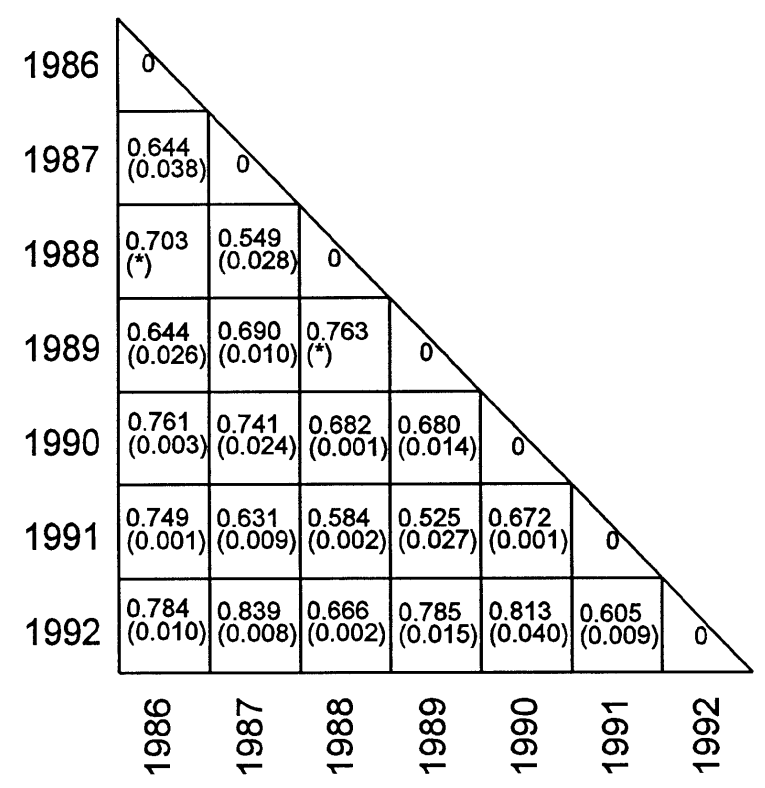

Fig. 11. Cophenetic correlation coefficients for all pairs of annual CY-dissimilarity matrices. Values in parentheses are the probabilities of significant differences determined by Mantel permutation tests $(10,000$ simulations) on all matrix pairs. Asterisks $(*)$ indicate no significant difference at the $0.01 \%$ level.

It is important to emphasize that this simply means that the patterns of inter-station dissimilarity (all 66 possible pairs of stations) were consistent between years, not necessarily that year-to-year dissimilarities in specific inter-station pairings were not significantly different; these temporal effects are explored below.

The use of 1986 zooplankton community composition as a baseline against which all subsequent years were compared within stations revealed that 1987 had the lowest CY-dissimilarity with the baseline at six of the 12 stations, while 1992 had the highest dissimilarity with the 1986 baseline at 10 of the 12 stations. Averaged over all stations, the yearly intra-station dissimilarities steadily increased $78 \%$ by 1992 (Fig. 12). The greatest rates of increase in yearly intra-station dissimilarity with 1986 baselines were found for Stations K42 and E51 (281\% and 224\% increases, respectively; Fig. 12). Trends were least evident at the Cook's Bay stations; Spearman's Rank correlation coefficients of 0.543, 0.429 and $0.600(\mathrm{n}=6)$, relating Stations C1, C6 and C9 1986 baseline CY-dissimilarities to subsequent years, were not significant $(P>0.1)$.

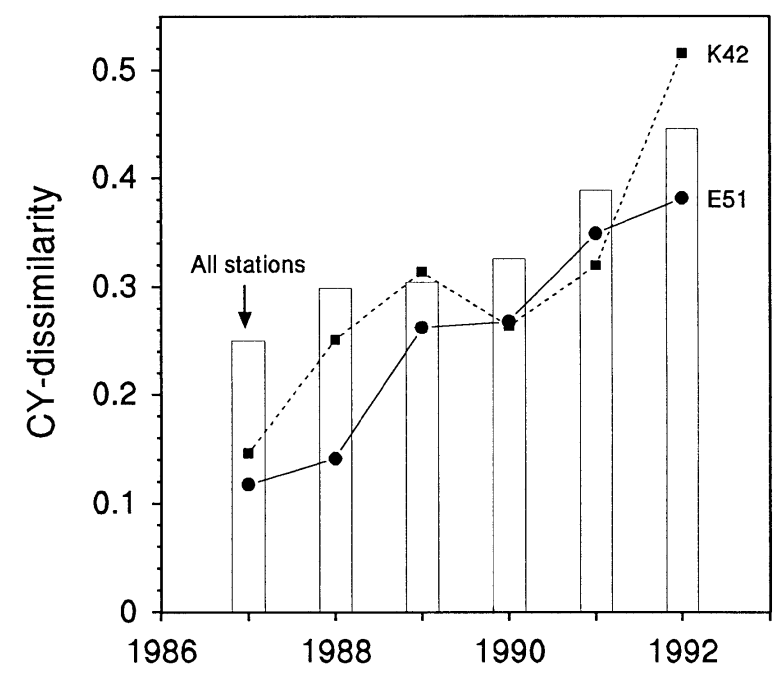

Fig. 12. Station K42 and E51 CY-dissimilarities of each year paired with its 1986 baseline zooplankton composition (all 45 taxa). Also shown are the average values for all 12 sampling stations.

These trends in community structure were the net results of many different patterns of change for many taxa. Such patterns included increasing densities over the 7-year period of Daphnia longiremis, Diaphanosoma birgei and declining densities of Daphnia pulicaria (Fig. 13). Several taxa including Daphnia g. mendotae (especially in Kempenfelt Bay), immature stages of cyclopoid copepods, an unidentified Daphnia species, D. parvula, Mesocyclops edax (especially in Kempenfelt Bay), Leptodiaptomus sicilis (in the main lake), Sida crystallina and Leptodora kindtii (especially in Cook's Bay) showed highest values in the middle years of the study. Ceriodaphnia spp. in Kempenfelt Bay and Cook's Bay were at their lowest densities during this time (Fig. 13). 

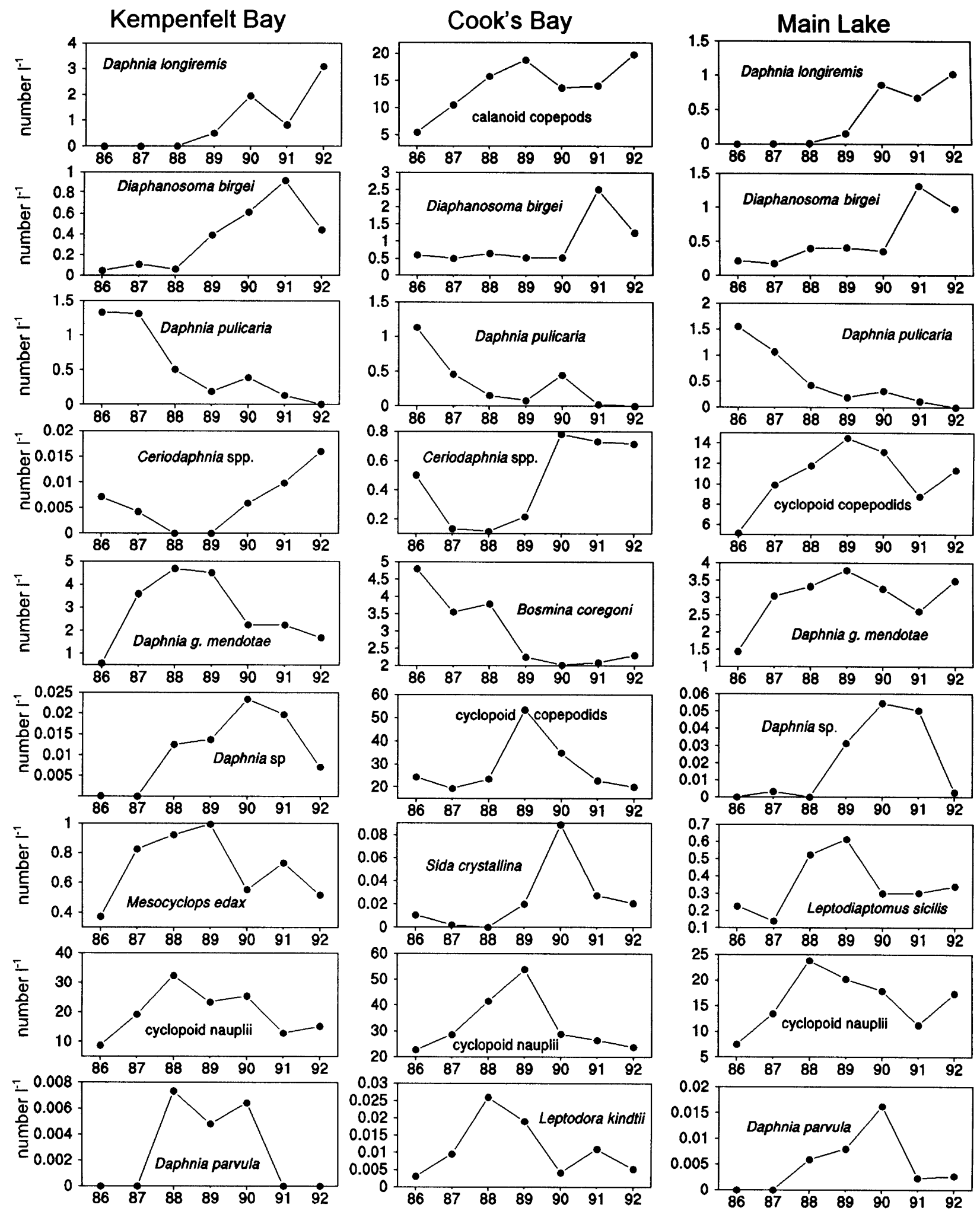

Fig. 13. May-October average densities of selected crustacean zooplankton taxa demonstrating trend patterns over the 7-year period (increasing, decreasing, mid-study peaks, or mid-study lows). The stations used to compile the averages for Kempenfelt Bay were: K38, K39 and K42; for Cook's Bay: C1, C6 and C9; for the main lake: S15, E50, E51 and K45. 


\section{DISCUSSION}

\subsection{Evidence for change}

We are reporting here on the first comprehensive investigation of the Lake Simcoe zooplankton. Previous studies have been qualitative, or limited in time and space (Brown \& Waring 1983; MacMillan 1985). Because those studies were undertaken only a few years prior to ours, there is little to be gained by trying to combine their data with ours for a more detailed examination of change in zooplankton community structure (notwithstanding differences in taxonomic resolution and sampling methods).

Part of Rawson's (1930) investigation of the bottom fauna of Lake Simcoe included stomach analysis of several fish species with a view to determining distributions of major food organisms in the diets of these fish. Because he recorded several zooplankton genera among the fish food organisms, and because of the long time interval between his study and ours, there is some merit in comparing the findings in qualitative terms. The major diet constituents of most fish species in Rawson's investigation consisted of immature stages of insects, amphipods, gastropods, decapods (crayfish) and small prey fish species; however, analyses of stomachs from 31 specimens of lake herring (Rawson's Leucichthys artedi $=$ Coregonus artedii) revealed a dominant zooplankton component comprised of the genera Bosmina, Daphnia, Cyclops, Diaptomus and Senecella. No subgeneric data on this group were provided by Rawson. Omitting the densities of immature forms, bosminids comprised $41 \%$ and daphnids, $30 \%$ of the total numbers of taxa identified in our samples, and are therefore in agreement with Rawson's finding of these groups in the lake herring stomachs.

Rawson's three copepod genera (Cyclops, Diaptomus and Senecella) prove more problematic in an attempt to relate these to present-day relative abundance mainly because of nomenclatural changes in the intervening 60 years. For example, Diacyclops, Acanthocyclops, Mesocyclops and Tropocyclops, were all abundant in our samples in contrast to the only Cyclops species in our samples, C. scutifer, which was a very minor element of the zooplankton in the 1980's and 1990's. It is likely that Rawson's "Cyclops" included one or more of these genera. A similar conclusion may be reached concerning Diaptomus, which we did not record in our samples. Rawson's "Diaptomus" was undoubtedly some combination of Leptodiaptomus and Skistodiaptomus, and if their combined relative proportion of the total zooplankton density in the late 1920's plankton was about the same as it was in our investigation (8\%), these large-bodied organisms could well have appeared in lake herring stomachs as dominant food items because of size-selective predation by lake herring. It is more difficult to make the same argument for Senecella, which Rawson (1930) includes in his list of dominant food items for Lake Simcoe lake herring. Only one spe- cies, S. calanoides, was found in our samples at densities averaging only $0.0009 \%$ of the average density of all other taxa. In our samples it ranked $44^{\text {th }}\left(2^{\text {nd }}\right.$ last) in overall abundance. Because of its large size, it too has the potential for concentration in lake herring stomachs well above its proportions in the plankton owing to sizeselective predation, providing it is relatively abundant in the plankton. But Senecella's rare occurrence in presentday samples suggests that it would have had to have been much more abundant than this 60 years ago in order to have been a major food item for lake herring. Rawson's lake herring stomach analyses were conducted over the May-October period and thus reflects the same part of the year represented by our sampling; any differences thus cannot be related to possibly higher winter densities of Senecella that were not captured by our sampling. While it is often difficult to quantitatively relate lake zooplankton community composition to fish stomach contents, the importance of Senecella in Lake Simcoe herring stomachs 60 years ago and its rare occurrence in the present-day zooplankton would suggest therefore that Senecella abundance in Lake Simcoe has decreased substantially since the late 1920's. Unfortunately, no other data apparently exist to allow further evaluations of possible long-term change of other Lake Simcoe zooplankton species.

On a short-term scale, our 7-year record suggested several lines of evidence for trends in community structure. There were progressive increases in the levels of CY-dissimilarity with the baseline year (1986) among all stations except the Cook's Bay stations. The greatest changes were at some main lake stations where CY-dissimilarities increased 3-fold. It is important to emphasize that these community structure changes do not simple reflect differences between the beginning and end of the study period, but that they were linear over the entire 7-year period, suggesting a possible long-term, ecosystem-level cause. These could include shifts in the food web function of the lake manifested in declining recruitment of rainbow smelt (Osmerus mor$d a x$ ) and lake herring over a coincident period of time (Lake Simcoe Fisheries Assessment Unit, fall index netting data). Other fish community structural changes occurring about the same time include an increased abundance of black crappie (Pomoxis nigromaculatus); however, the influence of this warm-water fish would likely be much less pronounced in the main lake than in Cook's Bay. Changes in black crappie abundance alone could not therefore be the reason for the zooplankton community changes which were much more pronounced in the main lake than in Cook's Bay, and in this respect are more consistent with possible declines in the abovementioned cold-water fish species. Abundant taxa with larger densities in the later than in the earlier years of the study include Diaphanosoma birgei and Daphnia longiremis and is consistent with decreased predation by smelt and lake herring. More thorough investigation of 
possible changes in zooplanktivore effects based on biomass values and possible length changes of selected zooplankton taxa (e.g. Mills \& Green 1987, Almond et al. 1996, Taylor \& Carter 1997) is planned for a future publication.

\subsection{Indicators of Trophic State}

While the relationships of certain crustacean zooplankton species to lake trophic state are sometimes inconclusive or contradictory (Ravera 1996), it is worth examining some elements of the Lake Simcoe zooplankton community with reference to the lake's pres??ent-day eutrophic (Cook's Bay) and mesotrophic (main lake) status. The scarcity of Senecella calanoides and the absence of another classic oligotrophic indicator calanoid, Limnocalanus macrurus (Gannon \& Stemberger 1978) in our Lake Simcoe samples suggests that the deep cold-water habitat that these species need is deficient in other requirements and precludes present-day development of substantial populations of these species in Lake Simcoe. This is consistent with the modelled historical loss of hypolimnetic dissolved oxygen in Lake Simcoe as phosphorus loading increased 3-fold since the end of the 18th century (Nicholls 1997). These species declined in parts of the Laurentian Great Lakes subjected to accelerated eutrophication (Gannon 1981). Encouragingly, another oligotrophic indicator, Leptodiaptomus sicilis is still present in Lake Simcoe in moderate densities. Perhaps another remnant of an earlier more oligotrophic state is Daphnia longiremis, which, of the eight Daphnia species we enumerated in the lake, ranked fourth in overall average density.

Several species indicative of more eutrophic states were common in our Lake Simcoe samples. These include Acanthocyclops vernalis, Chydorus sphaericus and Bosmina longirostris, of which the latter was demonstrated to replace Bosmina longispina in classic paleolimnological studies of long term change from oligotrophic to eutrophic states (Deevey 1942; Hasler 1947). On average, B. longirostris was 6000 times more abundant than B. longispina in Lake Simcoe samples.

Eleven crustacean zooplankters in Lake Simcoe accounted for $88 \%$ of the total average density of all recorded species in the lake, excluding immature forms. In descending order these were: Bosmina longirostris, Daphnia galeata mendotae, Eubosmina coregoni, Daphnia retrocurva, Diacyclops thomasi, Leptodiaptodiaptomus minutus, Mesocyclops edax, Tropocyclops extensus, Diaphanosoma birgei, Daphnia pulicaria and Skistodiaptomus oregonensis. That these are ubiquitous taxa with wide environmental tolerances (with the exception of $E$. coregoni and D. pulicaria) is demonstrated by the dominance by nine of them in northern Ontario lakes representing a wide range of lake morphometry, trophic state, hardness and other biotic and abiotic variables (Keller \& Pitblado 1989). Many of these were also included among the dominants in other north temperate regions of North America (Carter et al. 1980; Roff et al.
1981; Shaw \& Kelso 1992; Keller \& Conlon 1994; Stemberger \& Lazorchak 1994; Pinel-Alloul et al. 1995; Lougheed \& Chow-Fraser 1998) for which most of these lakes were of much smaller size than Lake Simcoe. But even among the largest lakes of temperate North America, some of these same taxa (e.g. Leptodiaptomus sicilis, L. minutus, Diacyclops thomasi, Bosmina longirostris, Daphnia retrocurva, and D. g. mendotae) are among the most common (Patalas \& Salki 1993). It is clear from these investigations that several crustacean species are of widespread occurrence and tolerate wide range of trophic states and other ecosystem properties.

Despite the commonalities of several elements of the Lake Simcoe zooplankton with other temperate North American lakes, there are differences even with lakes in relatively close geographic proximity that are worth pointing out. The northeastern United States harbors populations of copepods (e.g. Skistodiaptomus oregonensis, Leptodiaptomus minutus, Mesocyclops edax - all of which were abundant in Lake Simcoe during our study) that are clearly widespread in many lakes, but populations of others such as Skistodiaptomus pygmaeus, S. pallidus, Aglaodiaptomus spatulocrenatus, A. leptopus and Onychodiaptomus sanguineus, which were not found in Lake Simcoe, are not uncommon in a region just a few hundred $\mathrm{km}$ SE of Lake Simcoe (Stemberger 1995).

It is instructive to compare the number of species in the Lake Simcoe zooplankton with other lakes at north temperate latitudes, although strict comparisons are not advisable unless sampling efforts are comparable (Arnott et al. 1998). A reduction in sampling effort, illustrated in our data by considering three different levels of sample thinning, demonstrated reductions in the number of recorded species of $30-40 \%$ at each sample thinning step when species numbers were calculated first as 7year totals, then as mean annual totals and finally from individual samples. On average, 2-3 times as many taxa were recorded at any given Lake Simcoe sampling station for the entire 7-year period than was determined for individual samples. Similarly, Arnott et al. (1998) found that only $50 \%$ of the annual total number of species was detected in single samples from eight Canadian Shield lakes.

The standardized level of sampling and analytical effort across all Lake Simcoe sampling stations should permit a quantitative evaluation of possible environmental influences. Certainly there are links between numbers of taxa at stations and overall measures of community similarity. The combination of cluster analysis and NMDS ordination of CY-dissimilarity values has revealed that Station $\mathrm{C} 1$ near the mouth of Holland River in southern Cook's Bay had a very different zooplankton community structure than the other stations. Nicholls \& Tudorancea (2001a) also demonstrated this with a fuzzy clustering approach. There 
were several features of the zooplankton community structure at Station $\mathrm{C} 1$ that set it apart from the other stations. The numbers of species identified (36) was considerably higher at this location over all years and for an individual year (1992 with 31 species) than for any other station. There were five species found at Station $\mathrm{C} 1$ that were not found at any of the other stations, and four species recorded from other stations were never found at Station C1. There were differences too among more common species, like Alona spp, Daphnia parvula, Sida cyrstallina, Acanthocyclops vernalis and Eucyclops serrulatus, all of which were relatively abundant at Station C1, but not so at other locations. This is consistent with the known occurrence of these smallbodied taxa in warm-water, eutrophic or shoreline habitats (Stemberger \& Lazorchak 1994; Carter et al. 1995; Moore et al. 1996; Gaiser \& Lang 1998; Sarvala 1998).

While detailed characterization of Lake Simcoe zooplankton composition in relation to environmental variables will be the subject of another paper, it is worth presenting at this time some preliminary generalized observations based on the data analyses completed so far. The multivariate approaches used here were highly successful in identifying Station C1 as an "outlier" because of the uniqueness of the species assemblages during all years at this location. Intuitively, environmental factors can account for this; the proximity to the mouth of the Holland River, with its high load of dissolved and suspended solids, higher nutrient and phytoplankton levels, shallowest depth and consequently warmest water and most thoroughly mixed water column all must contribute to the unique zooplankton community structure at Station C1.

The local environmental conditions at Station C1 were different from any of the other Lake Simcoe sampling locations and included a shallow $(2.5 \mathrm{~m})$, warm and well-mixed water column, with May-October average total phosphorus and phytoplankton biomass averaging $23 \mathrm{\mu g}^{-1}$ and $0.82 \mathrm{mg} \mathrm{l}^{-1}$, respectively for the 1987-1992 period, $30 \%$ and $20 \%$ higher than corresponding values for nearby Station C6 (Nicholls 1995). Conversely, the analyses could not discriminate between the highly similar zooplankton communities at Stations E50 and E51, where station depth, fetch, and other limnological variables were very similar. So, pairs of stations showing high levels of similarity or dissimilarity of zooplankton community structure are consistent with our intuitive classification of these stations based on knowledge of their other ecosystem characteristics.

Similarly, some of the temporal differences identified by the multivariate analyses are in agreement with known environmental factors. For example, zooplankton community structure in 1986 and 1992 was significantly different from other years. Water levels in Lake Simcoe in 1986 were at record highs. Parts of the TrentSevern Waterway (which includes Lake Simcoe) were closed to recreational boat traffic in mid-summer because of high flows for the first time in its history. Low temperature records were set in the summer of 1992 in the aftermath of the Mount Pinatubo eruption. Undoubtedly there are limnological consequences for both of these extreme climate-related phenomena that could impact on zooplankton community structure by altering the production and availability of phytoplankton food and growth rates of certain species, the size and feeding of zooplanktivorous fish, etc.

While 1986 and 1992 were represented by extremes of zooplankton community structure that may be explained by variables such as water level or temperature anomalies for those years, it should be emphasized that zooplankton community structure changed steadily and linearly over the 7-year interval. This suggests some possible influences from longer term modifications of habitat (e.g. effects of continuing urbanization of the Lake Simcoe basin and associated toxicant loads, longterm climate change, and fish community structural changes). Future research needs to address all such environmental variables for their possible role in shaping Lake Simcoe zooplankton community structure.

\section{ACKNOWLEDGMENTS}

Funding for this work was provided by the Ontario Ministry of the Environment. We thank Mark and Vanessa Ledlie for most of the zooplankton sampling and Tania Hollister for organization of the raw data files. C.T. thanks Drs. G. Dixon, C.H. Fernando and W.D. Taylor in the Department of Biology, University of Waterloo for providing equipment and laboratory space for zooplankton sample analyses. K.N. acknowledges the provision of work space and general program support from the Ministry of Natural Resources, Lake Simcoe Fisheries Assessment Unit, the Ministry of the Environment and the Lake Simcoe Region Conservation Authority.

\section{REFERENCES}

Almond, M.J.R., E. Bentzen \& W.D. Taylor. 1996. Size structure and species composition of plankton communities in deep Ontario lakes with and without Mysis relicta and planktivorous fish. Can. J. Fish. aquat. Sci., 53: 315325 .

Arnott, S.E., J.J. Magnuson \& N.D. Yan. 1998. Crustacean zooplankton species richness: single- and multiple-year estimates. Can. J. Fish. aquat. Sci., 55: 1573-1582.

Brown, E. \& P. Waring. 1983. Identification of the Zooplankton Community at Three Limnological Stations on Lake Simcoe During the Summer of 1981. Ontario Ministry of Natural Resources, Lake Simcoe Fisheries Assessment Unit, Report 83-1: 21 pp.

Cao, Y., W.P. Williams \& A.W. Bark. 1997a. Similarity measure in river benthic Aufwuchs community analysis. Water Environment Research, 69: 95-106.

Cao, Y., A.W. Bark \& W.P. Williams. 1997b. A comparison of clustering methods for river benthic community analysis. Hydrobiologia , 347: 25-40.

Carter, J.C.H., M.J. Dadswell, J.C. Roff \& W.G. Sprules. 1980. Distribution and zoogeography of planktonic crustaceans and dipterans in glaciated eastern North America. Can. J. Zool., 58: 1355-1387. 
Carter, J.C.H., W.D. Taylor \& C. Tudorancea. 1995. A horizontal gradient in zooplankton community structure, and its implications for the relationships among mesozooplankton, microzooplankton, and phytoplankton. Arch. Hydrobiol., 133: 197-222.

Clarke, K.R. \& R.M. Warwick. 1994. Similarity-based testing for community pattern: the two-way layout with no replication. Mar. Biol., 118: 167-176.

Clarke, K.R. \& R.H. Green. 1988. Statistical design and analysis for a "biological effects" study. Mar. Ecol. Progress Series, 46: 213-226.

Deevey, E.S., Jr. 1942. Studies on Connecticut lake sediments III. Biostratonomy of Linsley Pond. Amer. J. Sci., 240: 233-264, 313-338.

Digby, P.G.N. \& R.A. Kempton. 1987. Multivariate Analysis of Ecological Communities. Chapman and Hall, New York: $206 \mathrm{pp}$

Evans, D.O., K.H. Nicholls, Y.C. Allen \& M.J. McMurtry. 1996. Historical land use, phosphorus loading, and loss of fish habitat in Lake Simcoe, Canada. Can. J. Fish. aquat. Sci., 53 (Suppl. 1): 194-218.

Gaiser, E.E. \& K.L. Lang. 1998. Distribution of cladoceran zooplankton among prairie pothole wetlands in northwest Iowa. J. Lake and Reserv. Manage., 14: 37-51.

Gannon, J.E. 1981. Changes in zooplankton populations in Lakes Erie and Ontario. Bull. Buffalo Soc. of Nat. Sci., 25: 21-40

Gannon, J.E. \& R.S. Stemberger. 1978. Zooplankton (especially crustaceans and rotifers) as indicators of water quality. Trans. Amer. Microsc. Soc., 97: 16-35.

Hassler, A.D. 1947. Eutrophication of lakes by domestic drainage. Ecology, 28: 383-395.

Keller, W. \& M. Conlin. 1994. Crustacean zooplankton communities and lake morphometry in Precambrian Shield lakes. Can. J. Fish. aquat. Sci., 51: 2424-2434.

Keller, W. \& J.R. Pitblado. 1989. The distribution of crustacean zooplankton in northern Ontario, Canada. J. Biogeography, 16: 249-255.

Kovach, W.L. 1993. MVSP - A Multivariate Statistical Pack age of IBM-PC's, ver. 2.1. Kovach Computing Services, Pentraeth, Wales, U.K

Lougheed, V.L. \& P. Chow-Fraser. 1998. Factors that regulate the zooplankton community structure of a turbid, hypereutrophic Great Lakes wetland. Can. J. Fish. aquat. Sci., 55: 150-161.

LSEMS. 1995. Lake Simcoe - Our Waters, Our Heritage. Lake Simcoe Environmental Management Strategy Implementation Program. Summary of Phase I Progress and Recommendations for Phase II. Lake Simcoe Region Conservation Authority. Newmarket, Ontario: $107 \mathrm{pp}$.

Ludwig, J.A. \& J.F. Reynolds. 1988. Statistical Ecology. John Wiley and Sons, New York.

MacIsaac, H.J. 1996. Potential abiotic and biotic impacts of zebra mussels on the inland waters of North America. Amer. Zoologist, 36: 287-299.

MacMillan, A. 1985. A Study of the Late Summer Limnetic Zooplankton Community of Lake Simcoe, 1983. Ontario Ministry of Natural Resources, Lake Simcoe Fisheries Assessment Unit, Report 1985-2: 60 pp.

McMurtry, M.J., C.C. Willox \& T.C. Smith. 1997. An overview of fisheries management for Lake Simcoe. J. Lake Reserv. Manage., 13: 199-213.

Mills, E.L. \& D.M. Green. 1987. Use of zooplankton size to assess the community structure of fish populations in freshwater lakes. North Am.. J. Fish. Manage., 7: 369-378.

Moore, M.V., C.L. Folt \& R.S. Stemberger. 1996. Consequences of elevated temperatures for zooplankton assemblages in temperate lakes. Arch. Hydrobiol., 135: 289-319.
Nicholls, K.H. 1995. Some recent water quality trends in Lake Simcoe, Ontario: implications for basin planning and limnological research. Can. Water Resources J., 20: 213-226.

Nicholls, K.H. 1997. A limnological basis for a Lake Simcoe phosphorus loading objective. J. Lake Reserv. Manage., 13: 189-198.

Nicholls, K.H. \& C. Tudorancea. 2001a. Application of fuzzy cluster analysis to Lake Simcoe crustacean zooplankton community structure. Can. J. Fish. aquat. Sci., 58: 231240 .

Nicholls, K.H. \& C. Tudorancea. (2001b). Identification of local gradients and spatial autocorrelation in the crustacean zooplankton community of Lake Simcoe (Ontario, Canada): under review.

Oksanen, J. \& P.R. Minchin. 1997. Instability of ordination results under changes in input data order: explanations and remedies. J. Vegetation Sci., 8: 447-454.

Patalas, K. \& A. Salki. 1993. Spatial variation of crustacean plankton in lakes of different size. Can. J. Fish. aquat. Sci., 50: 2626-2640.

Péladeau, N. \& Y. Lacouture. 1993. SIMSTAT: Bootstrap computer simulation and statistical program for IBM personal computers. Behavior Research Methods, Instruments \& Computers, 25: 410-413.

Philippi, T.E., P.M. Dixon \& B.E. Taylor. 1998. Detecting trends in species composition. Ecol. Appl., 8: 300-308.

Pinel-Alloul, B., T. Niyonsenga, \& P. Legendre. 1995. Spatial and environmental components of freshwater zooplankton structure. Ecoscience, 2: 1-19.

Podani, J. 1994. Multivariate Data Analysis in Ecology and Systematics - a Methodological Guide to the SYN-TAX 5.0 Package. Ecological Computations Series: Vol. 6: 316 pp.

Podani, J. 1997a. SYN-TAX 5.10-PC, Supplement to the User's Manual. Scientia Publ., Budapest.

Podani, J. 1997b. Explanatory variables in classifications and the detection of the optimum number of clusters. In: C. Hayashi et al. (Eds). Springer, Tokyo.

Ravera, O. 1996. Zooplankton and trophic state relationships in temperate lakes. Mem. Ist. ital. Idrobiol., 54: 195-212.

Rawson, D.S. 1930. The bottom fauna of Lake Simcoe and its role in the ecology of the lake. $\mathrm{Ph} . \mathrm{D}$. Thesis, University of Toronto Studies, Pub. Ont. Fish. Res. Lab. N. 40. Univ. of Toronto Press.

Roff, J.C., W.G. Sprules, J.C.H. Carter \& M.J. Dadswell. 1981. The structure of crustacean zooplankton communities in glaciated eastern North America. Can. J. Fish. aquat. Sci., 38: 1428-1437.

Sarvala, J. 1998. Ecology and role of benthic copepods in northern lakes. J. Marine Systems, 15: 75-86.

Shaw, M.A. \& J.R.M. Kelso. 1992. Environmental factors influencing zooplankton species composition of lakes in north-central Ontario, Canada. 1992. Hydrobiologia, 241: $141-154$.

Stemberger, R.S. 1995. Pleistocene refuge areas and postglacial dispersal of copepods of the northeastern United States. Can. J. Fish. aquat. Sci., 52: 2197-2210.

Stemberger, R.S., \& J.M. Lazorchak. 1994. Zooplankton assemblage responses to disturbance gradients. Can. J. Fish. aquat. Sci., 51: 2435-2447.

Tausch, R.J., D.A. Charlet, D.A. Weixelman, \& D.C. Zamudio. 1995. Patterns of ordination and classification instability resulting from changes in input data order. $J$. Vegetation Sci. 6: 879-902.

Taylor, W.D., \& J.C.H. Carter. 1997. Zooplankton size and its relationship to trophic status in deep Ontario lakes. Can.J. Fish. aquat. Sci., 54: 2691-2699.

Yan, N.D., \& T.W. Pawson. 1997. Changes in the crustacean zooplankton community of harp Lake, Canada, following invasion by Bythotrephes cederstromi. Freshwat. Biol., 37: 409-425. 